\title{
Cognitive Function in Multiple Sclerosis: a Subcortical Pattern of Neuropsychological Impairment?
}

\author{
CARLO GALTAGIRONE, GIOVANNI AUGUSTO GARLESIMO, \\ LUCIA FADDA and SABINA RONCACCI
}

Neurologic Clinic, 2nd University of Rome, Ospedale S. Eugenio, P. le dell'Umanesimo, 10, 00144

Roma, Italy

\begin{abstract}
In order to evaluate cognitive impairment in multiple sclerosis (MS) neuropsychological tests were administered to 25 patients with clinically definite disease. Four $(16 \%)$ showed diffuse cognitive impairment, whereas the others, compared with controls showed a specific deficit on tests known to be sensitive to frontal lobe damage. These results are interpreted in the light of current hypotheses relating to subcortical contributions in cognition.
\end{abstract}

\section{Introduction}

Multiple sclerosis (MS) is a chronic demyelinating disease of the central nervous system (CNS). The pathological lesions are mostly located in the white matter although small plaques may be found in grey matter and in the white-grey matter junction (Brownell and Hughes, 1962). Phases of exacerbation and periods of remission generally characterize the clinical course of the disease and a chronic-progressive course, rarely observed in the early stages, becomes frequent in advanced stages of the disease (Silberberg, 1977). Since demyelinating plaques can be located anywhere in the CNS, neurological signs and symptoms vary considerably. The most frequently observed symptoms reflect involvement of optic nerves (unilateral or bilateral visual loss), pyramidal tracts (limb weakness and spasticity), cerebellum (ataxia) and the medial longitudinal fasciculus (internuclear ophtalmoplegia) (McAlpine et al., 1955).

The occurrence of cognitive deficits is also accepted but there is disagreement about the frequency and qualitative features of mental impairment.

Values ranging from 0-3\% (Cottrell and Wilson, 1926; Sugar and Nadell, 1943; Kurtzke et al., 1972) to 60-70\% (Ombredane, 1926; Surridge, 1969) have been reported for dementia in MS (Table 1). In these studies it has been generally observed that mental impairment is mostly seen in the advanced stages of the disease in a context of severe physical disability (McKann, 1982) and frequently associated with dysphoric and anosognosic behaviour (Ombredane, 1926; Surridge, 1969; Brown and Davis, 1922; Kahana et al., 1971).

Neuropsychological studies also report variable prevalence figures for mental impairment in MS studies. Table 2 summarizes data derived from $0953-4180 / 91 / 030129+13 \$ 3.50 / 0$ 
TABLE 1. Prevalence of cognitive deterioration and associated emotional behaviour in MS derived from some clinical studies

\begin{tabular}{|c|c|c|c|c|}
\hline References & $\begin{array}{l}\text { Number of } \\
\text { MS subjects }\end{array}$ & $\begin{array}{c}\% \\
\text { Deteriorated } \\
\text { subjects }\end{array}$ & Emot & haviour \\
\hline Sachs-Friedman (1922) & 141 & $15 \%$ & & \\
\hline Cottrell--Wilson (1926) & 100 & $2 \%$ & $\begin{array}{l}\text { euphoria } \\
\text { depression }\end{array}$ & $\begin{array}{l}63 \% \\
10 \%\end{array}$ \\
\hline Ombredane (1929) & 50 & $72 \%$ & \multicolumn{2}{|c|}{$\begin{array}{l}\text { eurphoria correlated to } \\
\text { cognitive deterioration }\end{array}$} \\
\hline Sugar-Nadel (1943) & 28 & $0 \%$ & $\begin{array}{l}\text { euphoria } \\
\text { depression }\end{array}$ & $\begin{array}{l}50 \% \\
36 \%\end{array}$ \\
\hline Surridge (1969) & 108 & $61 \cdot 1 \%$ & \multicolumn{2}{|c|}{$\begin{array}{l}\text { euphoria correlated to } \\
\text { cognitive deterioration }\end{array}$} \\
\hline Kurtzke (1970) & 572 & $3 \%$ & & \\
\hline Kahana et al. (1971) & 295 & $25 \%$ & $\begin{array}{l}\text { euphoria } \\
\text { depression }\end{array}$ & $\begin{array}{l}5 \% \\
9 \%\end{array}$ \\
\hline
\end{tabular}

TABLE 2. Prevalence of cognitive impairment in $M S$ derived from various neuropsychological studies

\begin{tabular}{|c|c|c|c|c|}
\hline References & $\begin{array}{l}\text { Number of } \\
\text { subjects }\end{array}$ & \multicolumn{2}{|c|}{$\begin{array}{l}\% \text { Deteriorated } \\
\text { subjects }\end{array}$} & Tests \\
\hline Pratt (1951) & $\begin{array}{l}50 \\
64\end{array}$ & & $\begin{array}{l}15 \% \\
28 \%\end{array}$ & $\begin{array}{l}\text { Shipley Hartford test } \\
\text { Raven's } \\
\text { P.M. }\end{array}$ \\
\hline Baldwin (1952) & 32 & & $50 \%$ & $\begin{array}{l}\text { Hurt-Minnesota test for } \\
\text { organic brain damage }\end{array}$ \\
\hline Parsons et al. (1957) & 17 & $\begin{array}{l}\text { mildly } \\
\text { severely }\end{array}$ & $\begin{array}{l}41 \% \\
29 \%\end{array}$ & $\begin{array}{l}\text { Grassi block } \\
\text { substitution test }\end{array}$ \\
\hline Peyser et al. (1980) & 52 & & $55 \%$ & Halstead Category test \\
\hline De Smedt et al. (1984) & 46 & $\begin{array}{l}\text { mildly } \\
\text { severely }\end{array}$ & $\begin{array}{r}57 \% \\
8 \%\end{array}$ & WAIS \\
\hline Rao et al. (1984) & 44 & $\begin{array}{l}\text { mildly } \\
\text { severely }\end{array}$ & $\begin{array}{l}43 \% \\
20 \%\end{array}$ & $\begin{array}{l}\text { verbal and visual memory } \\
\text { verbal and visual memory; } \\
\text { Rush cognitive screening } \\
\text { examination }\end{array}$ \\
\hline Lyon-Caen et al. (1986) & 30 & & $60 \%$ & $\begin{array}{l}\text { WAIS, WCST, Wechsler } \\
\text { memory scale }\end{array}$ \\
\hline Beatty et al. (1988) & 38 & & $\begin{array}{l}75 \% \\
61 \% \\
45 \%\end{array}$ & $\begin{array}{l}\text { Digit symbol } \\
\text { Word fluency } \\
\text { Anterograde and remote } \\
\text { memory }\end{array}$ \\
\hline
\end{tabular}


some of these studies together with the types of tests used and the percentages of subjects obtaining deficient performances.

Neuropsychological data concerning the relationship between cognitive deficits and clinical variables are also controversial. In particular, the claim by Canter (1951) and Fink and Houser (1961) of a significant relation between cognitive impairment and degree of physical disability has not been confirmed by Marsh (1980) and Rao et al. (1985). These latter authors did not even find a significant correlation between cognitive impairment and duration of illness. Heaton et al. (1985) have reported a greater frequency of mental impairment in MS patients with a chronic-progressive form of the disease than in those with a relapsing-remitting one.

In addition to quantitative data concerning the frequency of mental deterioration, neuropsychological studies have been reported which assess qualitative features of cognitive impairment attempting to highlight possible relationships between structural changes and pattern of cognitive deficits. WAIS IQ testing has shown that MS patients obtain higher scores in verbal subtests than in performance ones (Canter, 1951; Reitan et al., 1971). On the basis of these data, the hypothesis of an asymmetrical pattern of cognitive impairment in MS patients, with more compromised visualspatial skills than linguistic functions, has been proposed. It must be noted, however, that the reliability of WAIS to offer specific information about single cognitive functions is questionable. In fact, various subtests appear so saturated with a general intelligence factor as to make them scarcely specific in assessing single cognitive functions. Furthermore, the correct execution of performance subtests of WAIS requires manual dexterity and speed, which are frequently deficient in MS patients. For this reason Rao (1986) has suggested that the impairment of fine motor coordination is a more parsimonious explanation than an asymmetrical pattern of cognitive deterioration to account for the lower scores obtained by MS patients on performance subtests of the WAIS.

More recently, studies devoted to assess cognition of MS patients have been based on neuropsychological tests able to give specific information on a wide range of cognitive functions. The most frequently documented deficits are concerned with retrieval memory and conceptual reasoning. In particular, a deficient immediate and delayed recall (Rao et al., 1984) and a deficit in the formation and shifting of concepts (Heaton et al., 1985; Rao and Hammeke, 1984) have been noted. Deficits of language on the other hand have only been rarely described (Olmos-Lau et al., 1977) and dyspraxia and visual-perceptual disorders have not yet been documented. Rao (1986) has suggested that a similar pattern of cognitive impairment, characterized by prevalent deficits of memory and conceptual reasoning with a preservation of linguistic, praxic and gnosic functions, occurs in subjects with prefrontal lesions. Moreover, in view of the fact that a frontal pattern of cognitive impairment has been demonstrated in demented (Pillon et al., 1986) and non-demented subjects (Taylor et al., 1986; Caltagirone et al., 1989a) affected by subcortical pathologies, the same author has proposed to include 
cognitive deficits observed in MS in the group of so-called subcortical dementias.

The aims of our study were:

1 to evaluate, by means of a suitable neuropsychological battery, the prevalence of diffuse cognitive impairment in a sample of subjects with definite MS;

2 to assess possible relationships between cognitive impairment and some clinical variables of the disease such as duration of illness, disability degree, clinical course and emotional behavior;

3 to verify the hypothesis that performance profile shown by MS patients is indicative of a specific impairment of such functions as concept formation and shifting aptitude generally subsumed by frontal lobes and frequently impaired in patients with subcortical pathologies.

\section{Material and methods}

In this study we have examined a sample of 25 subjects (22 females and three males) with clinical definite MS according to criteria proposed by McAlpine and coworkers (1972). Nineteen patients showed a relapsingremitting clinical course while the remaining six had a chronic-progressive one. At the time of the neuropsychological examination none of the patients were on steroid therapy and none of the individuals with a relapsingremitting course had an acute exacerbation. The degree of disability for every subject was established by means of the Disability Status Score (DSS, Kurtzke, 1965).

The control group was composed of 25 subjects affected by traumatic or inflammatory diseases of spinal cord not involving the Central Nervous System above the cervical region and matched according to sex, age and literacy with MS subjects. The clinical features and relative statistical comparisons between MS patients and control subjects are shown in Table 3.

The presence of dementia was established on neuropsychological grounds by means of the Mental Deterioration Battery (MDB). The MDB is composed of eight tests assessing mnesic, verbal, visuo-constructive and intellectual abilities. A detailed description of this test is described elsewhere

TABLE 3. Clinical features of $M S$ and control samples

\begin{tabular}{|c|c|c|c|}
\hline & $\begin{array}{c}M S \\
(n=25)\end{array}$ & $\begin{array}{l}\text { Controls } \\
(n=25)\end{array}$ & $p$ \\
\hline Age & $40 \cdot 1(11 \cdot 8)$ & $40 \cdot 3(11 \cdot 3)$ & n.s. \\
\hline Literacy (years of schooling) & $10 \cdot 0 \quad(3 \cdot 8)$ & $9 \cdot 8 \quad(3 \cdot 9)$ & n.s. \\
\hline DSS & $4 \cdot 9 \quad(1 \cdot 6)$ & $4 \cdot 5 \quad(1 \cdot 8)$ & n.s. \\
\hline Duration of illness (years) & $12 \cdot 3 \quad(7 \cdot 3)$ & $11 \cdot 9 \quad(6 \cdot 5)$ & n.s. \\
\hline
\end{tabular}

DSS = Disability Status Score. 
(Caltagirone et al., 1979). A subject is considered impaired when he obtains pathological scores on four or more of the eight tests. The cut-off points which in every test distinguish normal from pathological performances are calculated subtracting one standard deviation from the mean scores obtained by a large group of healthy subjects (Caltagirone et al., 1979). The MDB has been shown to be highly reliable in distinguishing between deteriorated and healthy subjects (over $90 \%$ of correctly classified patients in a population composed of 103 demented and 83 control subjects, Caltagirone et al., 1979).

For a more detailed neuropsychological examination of MS and control subjects, the eight tests forming the MDB where integrated with other tests so as to provide information concerning the following cognitive fields (tests forming MDB are indicated with *):

Language

Verbal memory

Visuospatial memory

Constructional praxia

General intelligence

Frontal functions
Token test $(\mathrm{T})$

(De Renzi and Vignolo, 1962)

Boston naming test (B)

(Kaplan et al., 1978)

Phrases construction* (PC)

(Gainotti et al., 1976)

Rey's 15 words (Rey, 1958): immediate recall* (RST) delayed recall* (RLT) recognition (Rec)

Digit span (DS) (Wechsler, 1945)

Digit span backward (DSB)

Immediate visual memory* (IVM)

(Gainotti et al., 1978)

Corsi test (C) (Corsi, 1969)

Corsi backward (CB)

Copy drawing designs* (CD)

(Gainott et al., 1977)

Copy designs with landmarks* (CDL)

Progressive Matrices '47* (PM '47)

(Raven, 1949)

Verbal analogies (SAT)

(Tarquini and Masullo, 1981)

Word fluency* (WF)

(Borkowski et al., 1967)

Temporal rules induction (TRI)

(Caltagirone et al., 1982)

Wisconsin card sorting test (WCST)

(Nelson, 1976)

Scores obtained on different tests of MDB were adjusted for age and literacy 
on the basis of normative data derived from a large population of healthy subjects.

Furthermore, MS patients underwent a depressive status evaluation using the Hamilton rating scale.

\section{Results}

Four out of $25 \mathrm{MS}$ subjects (16\%), on the basis of MDB were considered demented.

In order to assess possible correlations between MS patients' cognitive performances and some clinical variables of the disease, a Global Performance Index (GPI) for every subject was calculated according to standard criteria (Caltagirone et al., 1987).

The correlations between GPI and the different clinical aspects were measured by means of the Spearman rho test (Table 4). Non-significant correlations were found for: GPI and DSS score (Rho $=-0 \cdot 24 ; p=$ n.s.), GPI and depression scale score (Rho $=-0 \cdot 11 ; p=$ n.s.).

A trend toward significance was found for the correlation between GPI and duration of illness ( $\mathrm{Rho}=-0.38 ; p=0.06$ ).

A higher, though non significant, prevalence of diffuse cognitive impairment was detected $\left(\chi^{2}=1 \cdot 8 ; p=-\right.$ n.s. $)$ in the chronic-progressive cases $(2 / 6)$ than in the relapsing-remitting one $(2 / 19)$.

To evaluate the qualitative features of cognitive impairment exhibited by MS patients, the comparison between performances of MS and control groups on single tests were submitted to statistical analysis, utilizing Student's $t$ test. Since performance scores obtained on WCST do not fit a normal distribution, statistical analysis for this test was performed by means of a non-parametric test (Mann-Whitney $U$ test).

As shown in Table 5, significant differences were found for Word Fluency and for the different performance scores derived from WCST (number of criteria, perseverative errors and total errors). Marginally significant differences were obtained for Simple Analogies Test and for the Immediate Visual Memory.

TABLE 4. Correlations between Global Performance Index and clinical variables in the $M S$ sample

\begin{tabular}{llc}
\hline & GPI & $p$ \\
\hline Duration of illness & Rho $=-0.38$ & 0.06 \\
DSS score & Rho $=-0.24$ & n.s. \\
Depression scale score & Rho $=-0.11$ & n.s. \\
\hline
\end{tabular}

GPI = Global Performance Index; DSS $=$ Disability Status Score. 
TABLE 5. Performance scores obtained on various tests of neuropsychological battery by the whole sample of $M S$ and control subjects

\begin{tabular}{|c|c|c|c|c|}
\hline & $\begin{array}{c}M S \\
(n=25)\end{array}$ & $\begin{array}{c}\text { Controls } \\
(n=25)\end{array}$ & $t$ & $p$ \\
\hline $\begin{array}{l}\mathrm{T} \\
\mathrm{B} \\
\mathrm{PG}\end{array}$ & $\begin{array}{l}32 \cdot 8(2 \cdot 8) \\
44 \cdot 7(9 \cdot 1) \\
20 \cdot 0(5 \cdot 3)\end{array}$ & $\begin{array}{l}33 \cdot 9(2 \cdot 0) \\
48 \cdot 4(6 \cdot 8) \\
21 \cdot 8(3 \cdot 8)\end{array}$ & $\begin{array}{l}1 \cdot 6 \\
1 \cdot 6 \\
1 \cdot 3\end{array}$ & $\begin{array}{l}\text { n.s. } \\
\text { n.s. } \\
\text { n.s. }\end{array}$ \\
\hline $\begin{array}{l}\text { RST } \\
\text { RLT } \\
\text { Rec } \\
\text { DS } \\
\text { DSB }\end{array}$ & $\begin{array}{r}34.0(9.6) \\
7.5(3.4) \\
12.5(2.6) \\
5.9(1 \cdot 1) \\
4.0(1.0)\end{array}$ & $\begin{aligned} 38 \cdot 3 & (9 \cdot 2) \\
8 \cdot 7 & (2 \cdot 8) \\
13 \cdot 1 & (2 \cdot 2) \\
6 \cdot 0 & (1 \cdot 1) \\
4 \cdot 2 & (1 \cdot 0)\end{aligned}$ & $\begin{array}{l}1 \cdot 6 \\
1 \cdot 3 \\
0 \cdot 9 \\
0 \cdot 1 \\
0 \cdot 7\end{array}$ & $\begin{array}{l}\text { n.s. } \\
\text { n.s. } \\
\text { n.s. } \\
\text { n.s. } \\
\text { n.s. }\end{array}$ \\
\hline $\begin{array}{l}\text { IVM } \\
\text { C } \\
\text { CB }\end{array}$ & $\begin{array}{r}19 \cdot 3(2 \cdot 5) \\
4 \cdot 7(0 \cdot 6) \\
4 \cdot 2(0 \cdot 8)\end{array}$ & $\begin{array}{r}20 \cdot 5(1.4) \\
5 \cdot 0(1.0) \\
4.4(0 \cdot 6)\end{array}$ & $\begin{array}{l}2 \cdot 1 \\
1 \cdot 4 \\
0 \cdot 6\end{array}$ & $\begin{array}{r}<0.05 \\
\text { n.s. } \\
\text { n.s. }\end{array}$ \\
\hline $\begin{array}{l}\text { CD } \\
\text { CDL }\end{array}$ & $\begin{array}{r}9 \cdot 3(2 \cdot 3) \\
67 \cdot 3(4 \cdot 2)\end{array}$ & $\begin{array}{l}10 \cdot 1(1 \cdot 8) \\
68 \cdot 1(2 \cdot 6)\end{array}$ & $\begin{array}{l}1 \cdot 3 \\
0 \cdot 8\end{array}$ & $\begin{array}{l}\text { n.s. } \\
\text { n.s. }\end{array}$ \\
\hline $\begin{array}{l}\mathrm{PM}^{\prime} 47 \\
\text { SAT }\end{array}$ & $\begin{array}{l}24 \cdot 1(4 \cdot 0) \\
16 \cdot 2(4 \cdot 7)\end{array}$ & $\begin{array}{l}25 \cdot 5(4 \cdot 0) \\
18 \cdot 0(2 \cdot 1)\end{array}$ & $\begin{array}{l}1 \cdot 3 \\
1.9\end{array}$ & $\begin{aligned} & \text { n.s. } \\
= & 0.06\end{aligned}$ \\
\hline $\begin{array}{l}\text { WF } \\
\text { TRI }\end{array}$ & $\begin{array}{l}25 \cdot 8(7 \cdot 9) \\
37 \cdot 1(4 \cdot 1)\end{array}$ & $\begin{array}{l}32 \cdot 1(8 \cdot 1) \\
36 \cdot 7(4 \cdot 8)\end{array}$ & $\begin{array}{l}2 \cdot 8 \\
0 \cdot 4\end{array}$ & $\begin{array}{c}<0.01 \\
\text { n.s. }\end{array}$ \\
\hline $\begin{array}{ll}\text { WCST } & \text { criteria } \\
\text { total errors } \\
\text { pers. errors }\end{array}$ & $\begin{array}{r}3 \cdot 2(1 \cdot 6) \\
22 \cdot 6(8 \cdot 0) \\
9 \cdot 1(4 \cdot 9)\end{array}$ & $\begin{array}{r}4 \cdot 6(1 \cdot 5) \\
15 \cdot 6(7 \cdot 7) \\
7 \cdot 5(3 \cdot 4)\end{array}$ & $\begin{array}{c}z \\
2 \cdot 7 \\
2 \cdot 7 \\
2 \cdot 6\end{array}$ & $\begin{array}{l}<0.01 \\
<0.01 \\
<0.01\end{array}$ \\
\hline
\end{tabular}

$\mathrm{B}=$ Boston Naming Test; $\mathrm{C}=$ Corsi test $\mathrm{CB}=$ Corsi test Backward; $\mathrm{CD}=$ Copying Designs; $\mathrm{CDL}=$ Copying Designs with Landmarks; DS = Digit Span; DSB = Digit Span Backward;

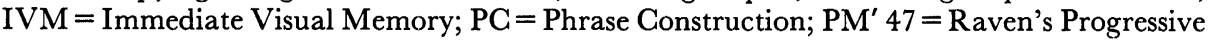
Matrices 1947; Rec $=$ Rey's 15 words Recognition; RLT = Rey's 15 words Delayed Recall; RST $=$ Rey's 15 words Immediate Recall; SAT $=$ Simple Analogies Test; $T=$ Token test; $\mathrm{TRI}=$ Temporal Rules Induction; WCST $=\mathrm{Wisconsin}$ Card Sorting Test; WF $=$ Word Fluency.

Brown and Marsden (1986) noted that, when pathological and healthy subjects' cognitive performances are compared, the differences found could result from the high percentage of demented subjects in the pathological group. For this reason, in order to point out the possible presence of selective cognitive deficits in MS subjects unaffected by dementia, we compared the performances of control subjects to those of $21 \mathrm{MS}$ patients not showing neuropsychological features of diffuse mental impairment. Even in this case, we found significant differences for Word Fluency and for number of criteria, perseverative errors and total errors obtained at WCST (Table 6).

\section{Discussion}

A prevalence of dementia in MS higher than one would expect in a normal population of similar age was found. It is difficult to compare these results 
TABLE 6. Performance scores obtained on various tests of neuropsychological battery by non-demented MS and control subjects

\begin{tabular}{|c|c|c|c|c|}
\hline & $\begin{array}{c}M S \\
(n=21)\end{array}$ & $\begin{array}{l}\text { Controls } \\
(n=25)\end{array}$ & $t$ & $p$ \\
\hline $\begin{array}{l}\mathrm{T} \\
\mathrm{B} \\
\mathrm{PC}\end{array}$ & $\begin{array}{ll}33 \cdot 6 & (2 \cdot 4) \\
46 \cdot 2 & (9 \cdot 1) \\
21 \cdot 1 & (3 \cdot 5)\end{array}$ & $\begin{array}{l}33.9(2.0) \\
48.4(6.8) \\
21.8(3.8)\end{array}$ & $\begin{array}{l}0.5 \\
0.9 \\
0.6\end{array}$ & $\begin{array}{l}\text { n.s. } \\
\text { n.s. } \\
\text { n.s. }\end{array}$ \\
\hline $\begin{array}{l}\text { RST } \\
\text { RLT } \\
\text { Rec } \\
\text { DS } \\
\text { DSB }\end{array}$ & $\begin{array}{r}36.4(8.2) \\
8.2(3.2) \\
12.9(2.5) \\
6.0(0.9) \\
4.0(1.0)\end{array}$ & $\begin{array}{r}38.3(9.2) \\
8.7(2 \cdot 8) \\
13.1(2 \cdot 2) \\
6.0(1 \cdot 1) \\
4.2(1 \cdot 0)\end{array}$ & $\begin{array}{l}0.7 \\
0.5 \\
0.4 \\
0.1 \\
0.5\end{array}$ & $\begin{array}{l}\text { n.s. } \\
\text { n.s. } \\
\text { n.s. } \\
\text { n.s. } \\
\text { n.s. }\end{array}$ \\
\hline $\begin{array}{l}\text { IVM } \\
\text { C } \\
\text { CB }\end{array}$ & $\begin{array}{r}20 \cdot 0(1 \cdot 6) \\
4 \cdot 7(0 \cdot 6) \\
4 \cdot 3(0 \cdot 8)\end{array}$ & $\begin{array}{r}20.5(1.4) \\
5.0(1.0) \\
4.4(0.6)\end{array}$ & $\begin{array}{l}1 \cdot 1 \\
1 \cdot 2 \\
0 \cdot 1\end{array}$ & $\begin{array}{l}\text { n.s. } \\
\text { n.s. } \\
\text { n.s. }\end{array}$ \\
\hline $\begin{array}{l}\mathrm{CD} \\
\mathrm{CDL}\end{array}$ & $\begin{array}{r}9 \cdot 8(1 \cdot 9) \\
68 \cdot 2(2 \cdot 1)\end{array}$ & $\begin{array}{l}10 \cdot 1(1 \cdot 8) \\
68 \cdot 1(2 \cdot 6)\end{array}$ & $\begin{array}{l}0 \cdot 5 \\
0 \cdot 2\end{array}$ & $\begin{array}{l}\text { n.s. } \\
\text { n.s. }\end{array}$ \\
\hline $\begin{array}{l}\mathrm{PM}^{\prime} 47 \\
\mathrm{SAT}\end{array}$ & $\begin{array}{l}25 \cdot 1(2 \cdot 6) \\
16 \cdot 9(4 \cdot 0)\end{array}$ & $\begin{array}{l}25 \cdot 5(4 \cdot 0) \\
18 \cdot 0(2 \cdot 1)\end{array}$ & $\begin{array}{l}0 \cdot 4 \\
1 \cdot 2\end{array}$ & $\begin{array}{l}\text { n.s. } \\
\text { n.s. }\end{array}$ \\
\hline $\begin{array}{l}\text { WF } \\
\text { TRI }\end{array}$ & $\begin{array}{l}26.3(7.9) \\
37.5(3.5)\end{array}$ & $\begin{array}{l}32 \cdot 1(8 \cdot 1) \\
36 \cdot 7(4 \cdot 8)\end{array}$ & $\begin{array}{l}2 \cdot 5 \\
0 \cdot 7 \\
z\end{array}$ & $\begin{array}{c}=0.02 \\
\text { n.s. }\end{array}$ \\
\hline $\begin{aligned} & \text { WCST } \text { criteria } \\
& \text { total errors } \\
& \text { pers. errors }\end{aligned}$ & $\begin{array}{r}3.5(1.6) \\
21.0(7.4) \\
8.9(4.7)\end{array}$ & $\begin{array}{r}4.6(1 \cdot 5) \\
15 \cdot 6(7 \cdot 7) \\
7.5(3.4)\end{array}$ & $\begin{array}{l}2 \cdot 2 \\
2 \cdot 1 \\
2 \cdot 0\end{array}$ & $\begin{array}{l}=0.02 \\
=0.03 \\
=0.04\end{array}$ \\
\hline
\end{tabular}

$\mathrm{B}=$ Boston Naming Test $\mathrm{C}=$ Corsi test $\mathrm{CB}=$ Corsi test Backward; $\mathrm{CD}=$ Copying Designs; $\mathrm{CDL}=$ Copying Designs with Landmarks; DS = Digit Span; DSB=Digit Span Backward; IVM = Immediate Visual Memory; PC = Phrase Construction; PM' $47=$ Raven's Progressive Matrices 1947; Rec $=$ Rey's 15 words Recognition; RLT = Rey's 15 words Delayed Recall; RST $=$ Rey's 15 words Immediate Recall; SAT $=$ Simple Analogies Test; T = Token test; $\mathrm{TRI}=$ Temporal Rules Induction; WCST $=\mathrm{Wisconsin}$ Card Sorting Test; WF $=$ Word Fluency.

with data derived from other studies. Tables 1 and 2 demonstrate the high variability of findings in previous clinical and neuropsychological studies. It is likely that the marked difference in reported prevalence of dementia in previous clinical studies reflects the use of different diagnostic parameters.

The lack of agreement even in results derived from neuropsychological studies requires further consideration. Firstly, it must be noted that many of these studies have assessed single cognitive functions (for example memory, conceptual reasoning, etc.) without more comprehensive survey of cognition, so it is impossible to determine whether deficient performance reflects a selective deficit or is indicative of a more global mental deterioration.

Furthermore, the reliability of Wechsler's intelligence scales (created to measure intelligence level in normal subjects) in assessing cognitive deterioration in pathological samples has been challenged on methodological grounds (Gainotti, 1977). 
We believe the prevalence of dementia found in our sample to be a reliable estimation of reality because it was obtained utilizing a battery of tests exploring a wide range of cognitive functions and expressly created to highlight the presence of diffuse mental impairment.

In agreement with previous cross sectional studies (Marsh, 1980; Rao et al., 1985) our data shows no correlation between cognitive deficits and the degree of physical disability. Similarly, the lack of negative correlation between cognitive performances and depressive scale scores are in agreement with previous reports (Peyser et al., 1980). Cognitive deficits in MS are probably therefore a direct consequence of the disease and not simply an expression of visuo-motor or emotional disturbances.

Finally, in agreement with Heaton et al. (1985), our data seem to suggest a higher prevalence of mental deterioration in the chronic-progressive forms of MS than in the relapsing-remitting ones.

Previous neuropsychology studies in unselected groups of MS subjects have shown reduced performance in a wide range of tests. The best documented deficits concern immediate and delayed recall (Rao and Hammeke, 1984) and conceptual reasoning capacity (Heaton et al., 1985; Rao and Hammeke, 1984). Comparing the performances of our MS group to those of the control group, significant differences were found only in two tests (WF and WCST) both known to be sensitive to frontal lobe damage. Marginally significant differences were noted on a test of general intelligence on verbal data (SAT) and on the Immediate Visual Memory test.

We excluded from our sample those MS patients who demonstrated neuropsychological evidence of diffuse mental impairment (dementia). However, even when these were excluded significant differences were demonstrated on "frontal" tests, confirming that a selective impairment of frontal functions is detectable in MS patients.

It is interesting to note that a similar pattern of frontal impairment has also been detected in other CNS diseases characterized by a subcortical involvement including Parkinson disease (Taylor et al., 1986; Caltagirone $e t$ al., 1989a; Pillon et al., 1986; Caltagirone et al., 1989b). Progressive Supranuclear Palsy (Pillon et al., 1986), Normal Pressure Hydrocephalus (Caltagirone et al., 1982; Berglund et al., 1979) and "etat lacunaire" (Ishii et al., 1986).

In an attempt to confirm the subcortical origin of cognitive impairment exhibited by MS patients, Beatty et al. (1988) have administered to a group of chronic-progressive MS patients a battery of tests expressly created to distinguish differential patterns of cognitive impairment in cortical and subcortical dementias. MS patients did badly not only on tests (such as Word Fluency, anterograde and remote memory tests) considered indicative of a subcortical dementia, but also in a naming test known to be typically compromised in cortical dementias. The authors concluded that cognitive impairment in MS shares features of both cortical and subcortical dementia. It must be pointed out, however, that when most deteriorated patients (Mini Mental State Examination score less than 28) were excluded from the MS sample, significant differences in comparison to control group were found only for Word Fluency and memory tests. 
Alzheimer's disease and MS patients have been compared on an extensive neuropsychological battery. While Alzheimer's patients obtained worse performances on tests exploring memory and language, MS patients performed at lower level than Alzheimer's patients on tests of auditory and visual sustained attention (Filley et al., 1989). The authors considered that these data supported the hypothesis of differential patterns of cognitive impairment in dementias caused by cortical (Alzheimer's disease) and subcortical (MS) pathological changes. The prevalent deficit in attention seen in the MS patients was interpreted as resulting from "a disruption of diffuse attentional system arising from the brain stem" and/or "a damage to pathways originating in prefrontal cortex and terminating in posterior cortical areas" (Filley et al., 1989).

The selective or prevalent impairment of frontal functions in subcortical pathologies has been generally interpreted as due to a reduction of afferent pathways projecting from subcortical structures to frontal areas (Taylor $e t$ al., 1986; Ishii et al., 1986; Javoy-Agid and Agid, 1980; Adams, 1980).

Ventricular widening without cortical atrophy has been documented in MS both by autopsy studies (Barnard and Triggs, 1974) and neuroradiological techniques (Cala et al., 1978). Moreover, Lumsden (1970) has pointed out, in a large sample of MS autopsied cases, that demyelinating areas are mainly localized in periventricular white matter and in the superior frontal gyrus. Ventricular enlargement, periventricular and prefrontal plaques could all produce damage to fibre tracts interconnecting frontal lobes and other cortical and subcortical areas of the CNS.

Our results reveal a prevalence of diffuse mental impairment among MS patients which was higher than expected and a selective frontal deficit in non-deteriorated patients. Further research, conducted on a larger population, is needed to confirm these findings.

\section{References}

Adams, R. D. (1980). Altered cerebrospinal fluid dynamics in relation to dementia and aging. In "Aging of the Brain and Dementia", (Eds L. Amaducci, A. N. Davison, P. Antuono) pp. 217-226. Raven Press, New York.

Baldwin, M. V. A. (1952). A clinico-experimental investigation into the psychologic aspects of multiple sclerosis. Fournal of Nervous and Mental Disease, 115, 299-343.

Barnard, R. D. and Triggs, M. (1974). Corpus callosum in multiple sclerosis. Journal of Neurology, Neurosurgery and Psychiatry, 37, 1250-1264.

Beatty, W. W., Goodkin, D. E., Monson, N., Beatty, P. A. and Hertsgaard, D. (1988). Anterograde and retrograde amnesia in patients with chronic progressive multiple sclerosis. Archives of Neurology, 45, 611-619.

Berglund, M., Gustafson, L. and Hagberg, B. (1979). Amnestic-confabulatory syndrome in hydrocephalic dementia and Korsakoff's psychosis in alcoholism. Acta Psychiatrica Scandinavica, 60, 323-333.

Borkowski, J. G., Benton, A. L. and Spreen, O. (1967). Word fluency and brain damage. Neuropsychologia, 5, 135-140.

Brown, R. G. and Marsden, C. D. (1986). Neuropsychology and cognitive functions in Parkinson's disease: an overview. In "Movement Disorders 2", (Eds G. D. Marsden and S. Fahn). Butterworth, London, 99-123. 
Brown, S. and Davis, T. K. (1922). The mental symptoms of multiple sclerosis. Archives of Neurological Psychiatry, 7, 629-634.

Brownell, B. and Hughes, J.F. (1962). The distribution of plaques in the cerebrum in multiple sclerosis. Fournal of Neurology, Neurosurgery and Psychiatry, 25, 315-320.

Cala, L. A., Mastaglia, F. L. and Black, J. L. (1978). Computerized tomography of brain and optic nerve in multiple sclerosis. Observations in 100 patients, including serial studies in 16. Fournal of Neurological Science, 36, 411-426.

Calltagirone, G., Gainotti, G., Masullo, C. and Miceli, G. (1979). Validity of some neuropsychological tests in the assessment of mental deterioration. Acta Psychiatrica Scandinavica, 65, 93-100.

Caltagirone, C., Gainotti, G., Masullo, C. and Villa, G. (1982). Neuropsychological study of normal pressure hydrocephalus. Acta Psychiatrica Scandinavica, 65, 93-100.

Caltagirone, C., Carlesimo, A., Nocentini U. and Vicari, S. (1987). Profili differenziali di compromissione neuropsicologica in pazienti con pseudodemenza depressiva e pazienti con forme iniziali di malattia di Alzheimer. Alzheimer Longevita' Geriatria, 3/4, 308-312.

Caltagirone, C., Carlesimo, A., Nocentini, U. and Vicari, S. (1989a). Defective concept formation in Parkinsonians is independent from mental deterioration. Fournal of Neurology, Neurosurgery Psychiatry, 52, 334-337.

Galtagirone, C., Carlesimo, A., Nocentini, U. and Vicari, S. (1989b). Differential aspects of cognitive impairment in patients suffering from Parkinson's and Alzheimer's disease: a neuropsychological evaluation. International Journal of Neuroscience, 44, (1-2), 1-9.

Canter, A.H. (1951). Direct and indirect measures of psychological deficit in multiple sclerosis. Fournal of General Psychology, 44, 3-50.

Corsi, P. M. (1969). Verbal memory impairment after unilateral hippocampal excision. Paper presented at the 40th Annual Meeting of the Eastern Psychological Association, Philadephia, April.

Cottrell, S. S. and Wilson, S. A. K. (1926). The affective symptomatology of disseminated sclerosis. A study of 100 cases. Fournal of Neurology and Psychopathology, 7, 1-30.

De Renzi, E. and Vignolo, L. A. (1962). The Token Test; a sensitive test to detect receptive disturbances in aphasia. Brain, 85, 665-678.

De Smedt, L. Swerts, M. Geutjens, J. and Medaer, R. (1984). Intellectual impairment in Multiple Sclerosis. In "Immunological and Clinical Aspects of Multiple Sclerosis", (Eds R. E. Gonsette and P. Delmotte). MTP Press, Lancaster.

Filley, C. M., Heaton, R. K., Nelson, L. M., Burks, J. S. and Franklin, G. M. (1986). A comparison of dementia in Alzheimer's disease and multiple sclerosis. Archives of Neurology, 46, 157-161.

Fink, S. L. and Houser, H. B. (1966). An investigation of physical and intellectual changes in multiple sclerosis. Archives of Physical and Medical Rehabilitation, 47, 56-61.

Gainotti, G. (1977). I disturbi dell'intelligenza. In "Neuropsicologia Clinica". Franco Angeli, Milano.

Gainotti, G. Caltagirone, G. and Miceli, G. (1976). Sui rapporti fra alcune prove di intelligenza verbale e lesioni focali monoemisferiche. Acta Neurologica, 31, 370-381.

Gainotti, G., Caltagirone, C. and Miceli, G. (1978). Immediate visual special memory in hemisphere-damaged patients: impairment of verbal coding and of perceptual processing. Neuropsychologia, 16, 501-505.

Gainotti, G., Miceli, G. and Caltagirone, C. (1977). Constructional apraxia in left braindamaged patients: a planning disorder? Cortex, 13, 109-118.

Heaton, R. K., Nelson, L. M., Thompson, D. S., Burks, J. S. and Franklin, G. M. (1985). Neuropsychological findings in relapsing-remitting and chronic-progressive multiple sclerosis. Journal of Consultative and Clinical Psychology, 53, 103-110.

Ishii, N., Nishihara, Y. and Imamura, T. (1986). Why do frontal lobe symptoms predominate in vascular dementia with lacunes? Neurology, 36, 340-345.

Javoy-Agid, F. and Agid, Y. (1980). Is the mesocortical dopaminergic system involved in Parkinson disease. Neurology, 30, 1326-30.

Kahana, E., Leibovitz, U. and Alter, M. (1971). Cerebral multiple sclerosis. Neurology, 21, 1179-1185. 
Kaplan, E. Goodglass, H. and Weintraub, S. (1978). "The Boston Naming Test". Kaplan E and Goodglass $\mathrm{H}$. Boston.

Kurtzke, J. F. (1965). Further notes on disability evaluation in multiple sclerosis, with scale modifications. Neurology, 15, 654-661.

Kurtzke, J. F., Beebe, G. W., Nagler, B., Auth, T. L., Kurland, L. T. and Nefzger, M. D. (1972). Studies on the natural history of multiple sclerosis, 6. Clinical and laboratory findings at first diagnosis. Acta Neurologica Scandinavica, 48, 19-46.

Lumsden, C. E. (1970). The neuropathology of multiple sclerosis. In "Handbook of Clinical Neurology", vol. 9 "Multiple Sclerosis and Other Demyelinating Diseases", (Eds P.J. Vinken and G. W. Bruyn). American Elsevier Publishing Co, New York, 217-309.

Lyon-Caen, O., Jouvent, R., Hauser, S., Chaunu, M., Benoit, N., Widlocher, D. and Lhermitte, F. (1986). Cognitive function in recent-onset demyelinating disease. Archives of Neurology, 43, 1138-1141.

Marsh, G. (1980). Disability and intellectual function in multiple sclerosis. Fournal of Nervous and Mental Diseases, 168, 758-762.

McAlpine, D., Compston, N. D. and Lumsden, C. E. (1955). "Multiple Sclerosis". Churchill Livingstone, Edinburgh.

McAlpine, D., Lumsden, C. E. and Acheson, E. D. (1972). "Multiple Sclerosis Reappraisal". Churchill Livingstone, Edinburgh.

McKahn, G. M. (1982). Multiple sclerosis. Annual Reviewes of Neuroscience, 5, 219-239.

Nelson, H. E. (1976). A modified card sorting test sensitive to frontal lobe defects. Cortex, 12 , 313-324.

Olmos-Lau, N., Ginsberg, M. D. and Geller, J.B. (1977). Aphasia in multiple sclerosis. Neurology, 27, 623-626.

Ombredane, A. (1929). Sur les troubles mentaux de la sclerose en plaques. Thèse de Paris.

Parsons, O. A., Stewart, K. D. and Arenberg, D. (1957). Impairment of abstracting ability in multiple sclerosis. Fournal of Nervous and Mental Disease, 125, 221-225.

Peyser, J. M., Edwards, K. R., Poser, C. M. and Filskov, S. B. (1980). Cognitive function in patients with multiple sclerosis. Archives of Neurology, 37, 577-579.

Pillon, B., Dubois, B., Lhermitte, F. and Agid, Y. (1986). Heterogeneity of cognitive impairment in progressive supranuclear palsy, Parkinson's disease and Alzheimer's disease. Neurology, 36, 1179-1185.

Pratt, R. T. C. (1951). An investigation of the psychiatric aspects of disseminated sclerosis. Fournal of Neurology, Neurosurgery and Psychiatry, 14, 326.

Rao, M. S. (1986). Neuropsychology of multiple sclerosis: a critical review. Fournal of Clinical and Experimental Neuropsychology, 8, 503-542.

Rao, S. M. and Hammeke, T. A. (1984). Hypothesis testing in patients with chronicprogressive multiple sclerosis. Brain and Cognition, 3, 94-104.

Rao, S. M., Hammeke, T.A., McQuillen, M. P., Khatri, B. O. and Lloyd, D. (1984). Memory disturbances in chronic progressive multiple sclerosis. Archives of Neurology, 41, $625-631$.

Rao, S. M., Glatt, S., Hammeke, T. A., McQuillen, M. P., Khatri, B. O., Rhodes, A. M. and Pollard S. (1985). Chronic-progressive multiple sclerosis: Relationship between cerebral ventricular size and neuropsychological impairment. Archives of Neurology, 42, 678-682.

Raven, J. C. (1949). Progressive matrices (1947), Sets A, Ab, B: "Board and Book Forms". Lewis, London.

Reitan, R. M., Reed, J. C. and Dyken, M. (1971). Cognitive, psychomotor, and motor correlates of multiple sclerosis. Journal of Nervous and Mental Diseases, 153, 218-224.

Rey, A. (1958). Memorisation d'une serie de 15 mots en 5 répetitions. In 'L'Examen Clinique en Psychologie", (Ed. A. Rey). Presses Universitaire de France, Paris.

Sachs, B. and Friedman, E. D. (1922). General symptomatology and differential diagnosis of disseminated sclerosis. Archives of Neurological Psychiatry, 7, 551-560.

Silberberg, D. H. (1977). Multiple sclerosis. In "Scientific Approaches to Clinical Neurology", Vol. 1. (Eds E. S. Goldensah and S. H. Appell). Lea \& Febiger, Philadelphia.

Sugar, C. and Nadell, R. (1943). Mental symptoms in multiple sclerosis: a study of 28 cases with review of the literature. Journal of Nervous and Mental Diseases, 98, 267-280. 
Surridge, D. (1969). An investigation into some psychiatric aspects of multiple sclerosis. British Fournal of Psychiatry, 155, 749-764.

Taylor, A. E., Saint-Cyr, J.A. and Lang, A.E. (1986). Frontal lobe dysfunction in Parkinson's disease. The cortical focus of neostriatal outflow. Brain, 109, 845-883.

Tarquini, D. and Masullo, C. (1981). Cognitive impairment and chronic alcohol abuse: a neuropsychological study. Drug and Alcohol Dependence, 8, 103-109.

Wechsler, D. (1945). A standardized memory scale for clinical use. Fournal of Psychology, 19, 87. 


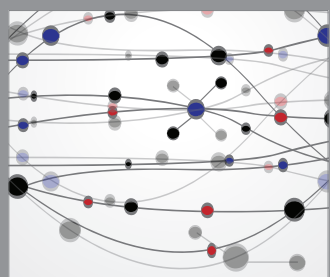

The Scientific World Journal
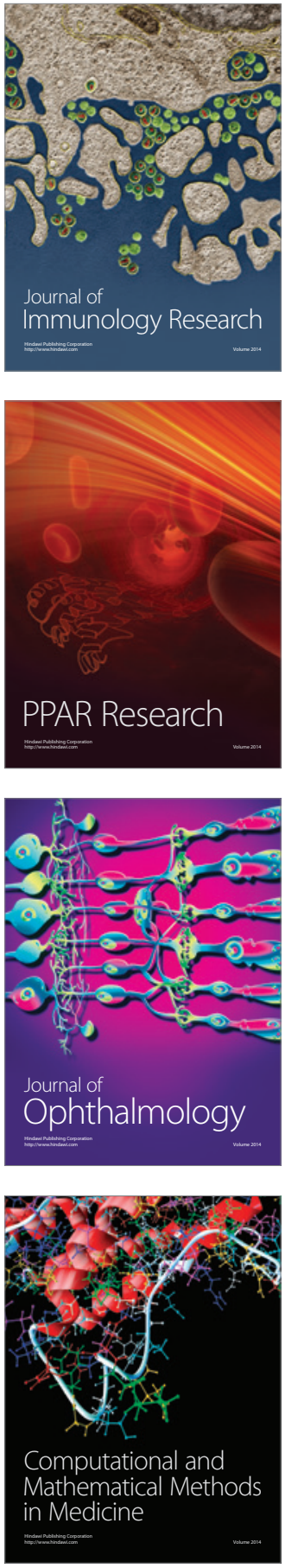

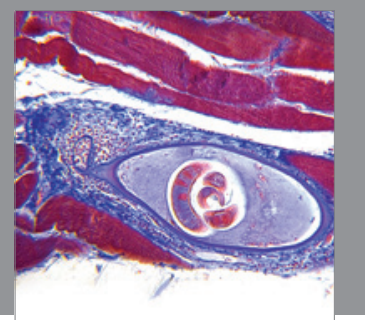

Gastroenterology

Research and Practice
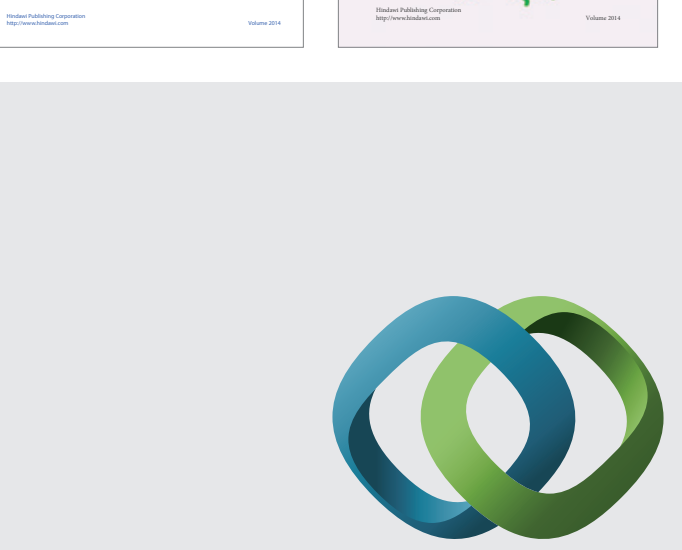

\section{Hindawi}

Submit your manuscripts at

http://www.hindawi.com
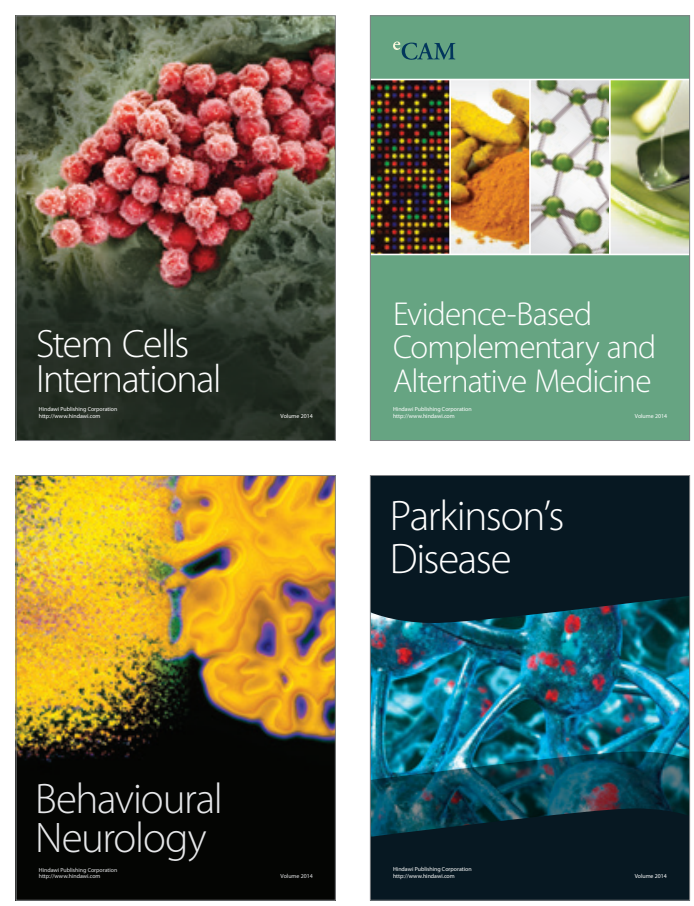

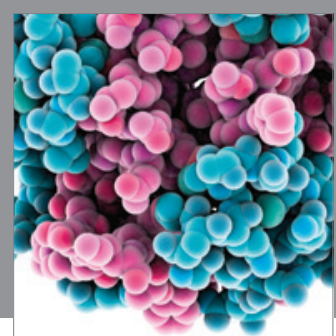

Journal of
Diabetes Research

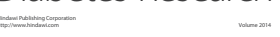

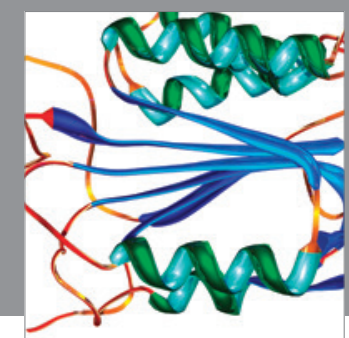

Disease Markers
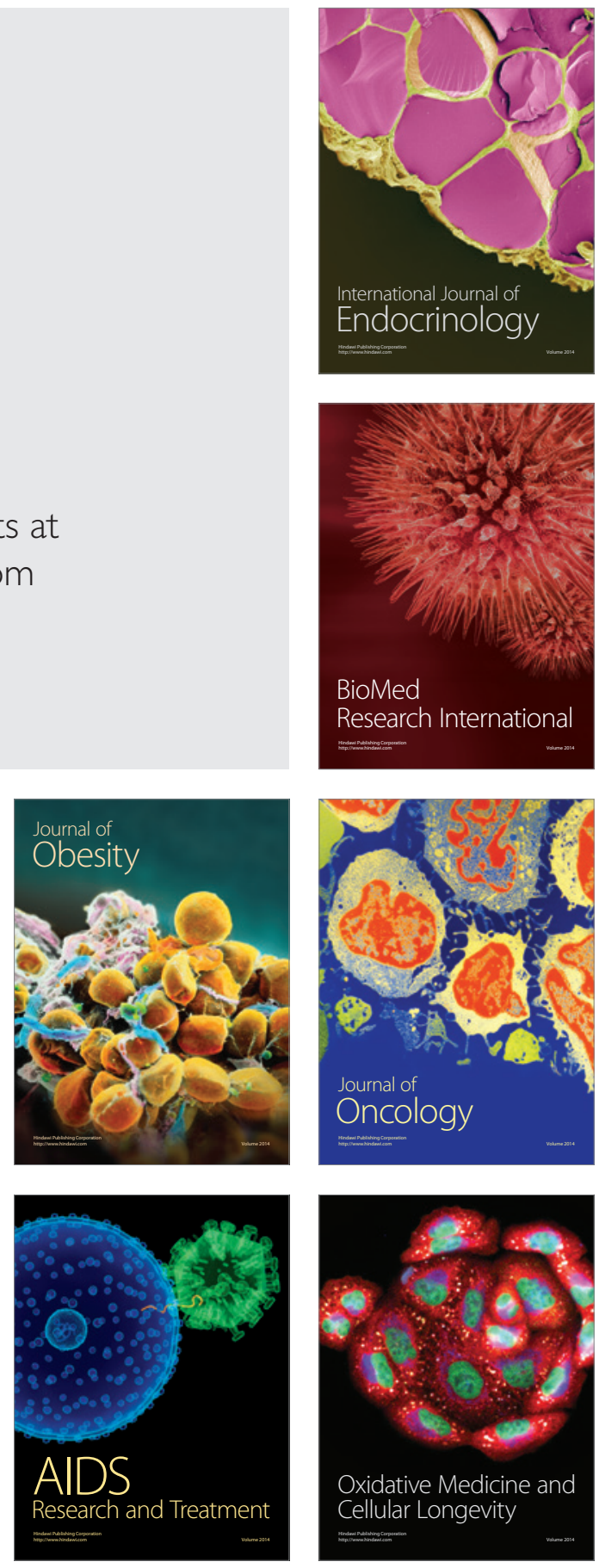